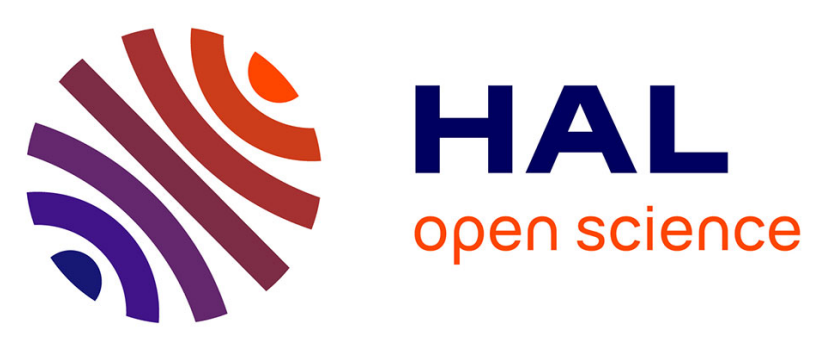

\title{
Necessities and problems of coupling climate and socioeconomic models for integrated assessments studies from an economist's point of view
}

Minh Ha-Duong

\section{- To cite this version: \\ Minh Ha-Duong. Necessities and problems of coupling climate and socioeconomic models for inte- grated assessments studies from an economist's point of view. Goals and Economic Instruments for the Achievement of Global Warming Mitigation in Europe, ed. by Jürgen Hacker and Arthur Pelchen, Kluwer Academic Publisher, pp.39-54, 1999. halshs-00007466}

\section{HAL Id: halshs-00007466 \\ https://shs.hal.science/halshs-00007466}

Submitted on 21 Dec 2005

HAL is a multi-disciplinary open access archive for the deposit and dissemination of scientific research documents, whether they are published or not. The documents may come from teaching and research institutions in France or abroad, or from public or private research centers.
L'archive ouverte pluridisciplinaire HAL, est destinée au dépôt et à la diffusion de documents scientifiques de niveau recherche, publiés ou non, émanant des établissements d'enseignement et de recherche français ou étrangers, des laboratoires publics ou privés. 
EU Advanced study course 1997: "Goals and Economic Instruments for the Achievement of Global Warming Mitigation in Europe"

\section{Necessities and problems of coupling climate and socioeconomic models for integrated assessments studies from an economist's point of view \\ Minh Ha-Duong \\ Centre International de Recherches sur l'Environnement et le Développement. CIRED, 1 rue du 11 Novembre, F92120 Montrouge, France. haduong@msh-paris.fr}

\section{Summary}

This presentation has two parts. The first part is more theoretical. We will examine the definition of Integrated Assessment Models of Climate Change and identify their main aims. We will also have look at the differences between climate and socioeconomic models. The second part will be applied. We present the Dynamics of Inertia and Adaptability Model (DIAM). That model will be used to study some of the fundamentals economic parameters of IAMs: the discount rate, the technical progress rate, the flexibility of energy systems, uncertainty and the final concentration target. We won't try to be exhaustive, see Weyant ${ }^{1}$ leading author of the corresponding IPCC chapter for that. Our goal is simply to convince the reader that these non realistic models can profitably be used to analyse real issues.

\section{Why put together climate and socioeconomic models?}

An Integrated Assessment Model (hereafter IAM), is a model that combine knowledge from a wide range of disciplines to provide insights that would not be observed through traditional disciplinary research. They are used to explore possible states of human and natural systems, analyse key questions related to policy formulation and help set research priorities (IPCC, 1995). This very broad class of models could also be called applied inter-disciplinary models.

These are not specific to the Climate Change, and there has been past exemple of integrated assessment of major environemental issues, as the european acid rain study RAINS. The main component of a climate change IAM can be graphically represented as in Figure 1. An IAM model will cover all or part of these boxes. It doesn't have to include all of them, for exemple a model of concentrations arising from the use of energy would qualify as a 'partial' IAM. If a model does represents all the aspects, then we can call it a or 'full' scale model. Typically, some boxes will be more detailled than others. 
Ha-Duong M. (1997) Necessities and problems of coupling climate and socioeconomic models for integrated assessments studies from an economist's point of view

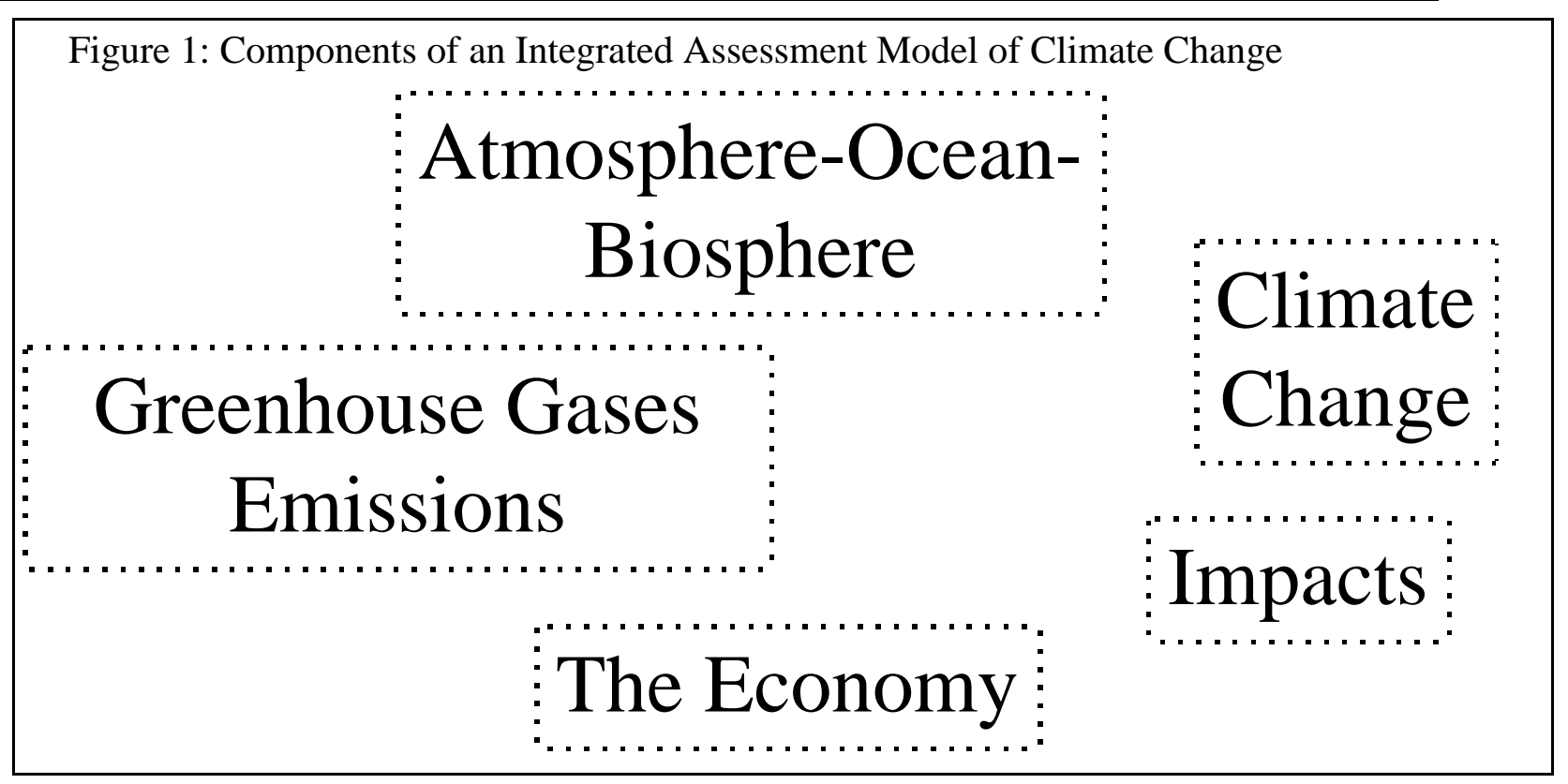

Because IAMs are defined very broadly, it is no surprise that they can be everything from very compact to very large. So there is no "best" way of building these models and no standard interface with the policy makers or the rest of the scientific community. As Table 1 illustrates, an extremely wide variety of computing tools are currently used. However, models tend to be divided in two categories, as integrated assessment seems to be caught between two traditions: the tradition of natural sciences, especially physics, established for more than three centuries and the traditions of social sciences which are only around 50 years old.

The first tradition describes physical phenomena that can be qualified as «pushed by the past ». These are treated in the framework of differential equations or finite difference equations. They are accessible through models where the flow of the calculation follows the « natural time »: Given the state of the system at date 0 , state at date 1 is computed first, then date 2 is examined..., recursively up to date T. In the second tradition, the phenomena are «driven by the future ». In economics and human affairs, there is often co-ordination (like general equilibrium), the existence of anticipations or a goal. Such phenomena can be best studied in the context of intertemporal optimisation where an optimal path is computed globally, taking into account initial and final conditions, as well as limited resources conditions. From a computational point of view, the solution is sought using the vector of states $\mathbf{V}=\left(\mathrm{S}_{1}, \mathrm{~S}_{2}, . ., \mathrm{S}_{\mathrm{T}}\right)$. The number of generic equations can be small, but multiplied by

Table 1 : Some models and their programming environment.

\begin{tabular}{|l|l|}
\hline Langage & Models \\
\hline GAMS & MERGE, DICE, ALICE \\
Mathematica & DIAM \\
PASCAL, FORTRAN 90 & FUND, MiniCAM, PAGE \\
STELLA, proprietary langage (M, DEMOS) & IMAGE, TARGETS, ICAM \\
\hline
\end{tabular}


Ha-Duong M. (1997) Necessities and problems of coupling climate and socioeconomic models for integrated assessments studies from an economist's point of view

the number of time periods, probabilistic outcomes, agents, production technologies and economic goods, they can generate a large, non linear, optimisation problem.

The question of the magnitude of global warming illustrates a typical physical phenomena "pushed by the past". The question of building international co-operation to reduce polluting emissions is "driven by the future", because anticipations play the main role in it. Models about economic responses to the issue of global warming needs to integrate human activities (demography, growth, the energy sector, agriculture, forestry ...) with the evolution of the terrestrial environment (the climate, the carbon cycle...). By essence, this is at the confluence of the two traditions defined above, so the division line of Table 2 is no waterproof. Yet today, two types of models are build in our field:

- policy analysis models, recursively calculated and usually quite detailed, as the IMAGE model by Rotmans?.

- policy optimisation models, intertemporally calculated and usually rather compact, as DIAM; DICE (Nordhaus ${ }^{8}$ ); or MERGE (Manne \& Richels ${ }^{9}$ ).

Policy analysis simulation models raise problems when it comes to analysis with scarce resources (like fossil fuel resources) or environmental constraints (like a ceiling on $\mathrm{CO}_{2}$ concentration). They tend to lead to «overshoot and collapse », and to have many ad hoc parameters. For these reasons, a lot of analysts prefer intertemporal models. This implies a modelling environment that is adequate to solve large optimisation programs. The GAMS language is often chosen, as it is a user friendly interface to powerful solvers. There are many different solvers, each adapted to different kind of optimisation problem : linear programming, non linear programming with $M I N O S$, integer programming with ZOOM, and so on. But this choice is done at the expense of the commodity of a higher symbolic expression of the model, as possible in Mathematica, for example.

Many other researcher prefer to use more general programming langages such as FORTRAN or PASCAL. It allows them to do both optimisation and simulation for quite detailled models. The price for this freedom, of course, is that the complexity of code management increases considerably. This is a reason why pure simulation models only are often written is specialized langages like STELLA. Those environments allows one to developp quickly and efficiently a processes-oriented model, in the same way that engineers modelize the production process of a factory.

In the long run, however, notwithstanding calculation limits of computers, the two types of models might converge as the equations

Table 2: Conceptual differences between Climate and Socioeconomic models

\begin{tabular}{|l|l|}
\hline \multicolumn{1}{|c|}{ Climate } & Socioeconomic \\
\hline Prediction & Projection \\
Causality & Anticipations \\
Simulation & Optimisation \\
Recursive & Intertemporal \\
\hline
\end{tabular}
are mainly the same, the main difference being more in the way the solution is sought. 
Ha-Duong M. (1997) Necessities and problems of coupling climate and socioeconomic models for integrated assessments studies from an economist's point of view

\section{IAMs in action: The WRE versus S controversy.}

Our goal in that paragraph is just to show that IAMs are a useful tool for discussing climate change policy. We will do so by giving an very specific exemple that, we believe, is characteristic of the use of IAMs in our field.

Stabilisation of greenhouse gas concentrations implies switching from the present growing emissions trend to a decreasing emissions path. That raises many complex issues that can't be adressed all at the same time. In what follows, we neglected the multiplicity of countries and of greenhouse gases, to focus on the question of the timing of abatement: "How fast should we reform the energy systems to use less fossil fuels ?"

Wigley, Richels and Edmonds ${ }^{2}$ (WRE) considered different emission pathways towards a given atmospheric $\mathrm{CO}_{2}$ concentration, and explained that extensive early abatement would not be a cost-effective way to meet concentration targets of about 450ppm or higher. Here we build upon their work by incorporating keys economic parameters into an explicit modelling framework which analyses least-cost pathways, and examine the sensitivity of pathways with respect to the target, inertia of the system, and discounting.

The IPCC's Second Assessment Report notes that «The choice of abatement paths involves balancing the economic risks of rapid abatement now (that premature capital stock retirement will later be proven unnecessary), against the corresponding risks of delay (that more rapid reduction will then be required, necessitating premature retirement of future capital)». WRE's paper examines different possible emission pathways towards stabilising atmospheric $\mathrm{CO}_{2}$ concentrations, and presents reasons why pathways involving little early departure from reference emission trends would be cheaper than strong immediate departure due to the effects of discounting, existing capital stock and of technological progress. First, technical progress implies that in the future, reforming the energy system will be easier. Second, discounting makes the present value of any cost incurred less if it is deferred. Third and finally, the existing installed physical capital stock implies that any reform should start very slowly: there is inertia in energy systems.

We explore the balance between costs of too early abatement and economic risks of delay by incorporating some of the economic considerations highlighted by WRE directly into a stylised model that optimises the time-path of emissions under a stabilisation constraint. Our analysis highlights two particular features of the decision-problem:

- The issue of capital stock utilisation and turnover reflects a broader question about the inertia of energy systems, that for consistency must be applied to the whole emissions pathway.

- The problem we face is to adopt a prudent strategy in the face of ignorance about the appropriate ultimate target. We are not likely to know soon at what concentration level dangerous interference with the climate system would occur, so the problem is stochastic in nature. We may for example adopt short term abatement targets consistent with a $550 \mathrm{ppm}$ concentration ceiling and be forced in a second step to switch toward a lower or higher ceiling, but lowering the ceiling would imply an accelerated abatement in order to outweight the inertia due to the timelife of greenhouse gases in the climate system. 
Ha-Duong M. (1997) Necessities and problems of coupling climate and socioeconomic models for integrated assessments studies from an economist's point of view

Our numerical exploration of these issues shows that both inertia and uncertainty increase the potential cost of deferring emissions abatement, and the combination of these factors leads to much stronger abatement in early decades than either in isolation.

\section{The DIAM 2 Model}

As a complete example of an IAM, we use a compact intertemporal optimization model, DIAM, which is developed from an initial exploration in $^{3}$. ven assumptions concerning the discount rate, abatement costs, and the rate of autonomous technical progress in carbonsaving technologies, DIAM determines the least-cost $\mathrm{CO}_{2}$ emission pathway consistent with staying below a given or stochastic concentration ceiling.

Table 3 specifies the model. $\mathrm{CO}_{2}$ emissions $\mathrm{E}(\mathrm{t})$ accumulate in the atmosphere according to a perturbation response function calibrated against Wigley's carbon cycle model. $\mathrm{CO}_{2}$ emissions in the absence of any abatement increase by $2 \% / y r$ linearly up to 2100 , approximating the IPCC central reference scenario IS92a. Deviations from the reference emissions are assumed to incur a positive cost. The model finds the pathway of abatement $x(\mathrm{t})$ that minimises the present value of total abatement costs, discounted at an annual rate $\rho$. Abatement costs decline due to assumed exogenous technological progress at a rate $r$, which we take as $1 \% / y r$. We explore values of $3 \%$ and $5 \%$ per year for the societal discount rate.

The abatement cost at time $\mathrm{t}$ is a quadratic function of both the degree of abatement $x(\mathrm{t})$ and the rate of abatement $x^{\prime}(\mathrm{t})$. By adding a term that depends upon the rate of abatement, the model captures inertia in the system. Costs are scaled according to the size of the reference system and assumed exogenous technical progress at rate $r$, to give equation 6 .

Parameters $\mathrm{c}_{\mathrm{a}}$ and $\mathrm{c}_{\mathrm{b}}$ can be calibrated to various assumptions about abatement costs and this affects the economic acceptability of different stabilisation levels, but the optimal pathway under a specified stabilisation constraint does not depend on their absolute values, only upon the ratio $c_{b} / c_{a}$. Its square root $\tau=\left(c_{b} / c_{a}\right)^{1 / 2}$ is a duration that we can interpret as the 'characteristic time' for changes in the global energy system. If we interpret $\tau$ as the exponential half life time of equipment, then it is related to the annual depreciation rate of capital $\delta$, by $\tau=(\ln 2) / \delta$.

Note that in reality there are also many other sources of inertia than capital stock lifetime in energy production. New energy sources have taken about 50 years to penetrate from $1 \%$ to only $50 \%$ of their ultimate potential. Time is also needed to remove market and institutional barriers to the diffusion of innovations and obstacles due to imperfect information and imperfect foresight. Moreover energy demand depends upon investments in buildings, transport and urban infrastructures whose effect may last more than 50 years. We take $\tau=50$ years as our initial value.

The purely technical inertia of capital stock in the energy system corresponds to the lifetimes of household equipment, power stations, cars or refineries, typically 10-40 years. A value $\tau_{\text {low }}=20$ years, which corresponds to capital depreciation at $\delta=4 \% / y r$, offers a lower value for inertia. Our results using this ratio are comparable to the results of economic / energy system models that do not embody institutional or larger infrastructural inertia. For example, as shown below, with $\tau=20$ years we recover modest optimal reduction levels in 2020 when stabilising at 550ppm, as in the economic studies cited by WRE.

Note that even the lower value implies high transitional costs for extreme rates of change. For example, if we compact a $20 \%$ emissions reduction into the central year of a 20 year period, the cost over the period is about 13 times as high as when the reductions are spread 
Ha-Duong M. (1997) Necessities and problems of coupling climate and socioeconomic models for integrated assessments studies from an economist's point of view

evenly across the period; with $\tau=50$ years, the ratio is about 18 . This could reflect the whole welfare impacts associated with sudden forced retirement of capital and associated shocks to labour and financial structures. In practice the model selects paths that never approach such extreme conditions, and transitional costs in the optimal paths are neither negligible nor predominant, as shown in Table 4 below.

The specification choosen in DIAM allows to describe a situation in which the permanent costs are low over the long run, and the transition costs high. An alternative specification of the adjustment costs would be to interpret $x^{\prime}$ as only related to the rate investment in the energy sector. As long as it is lower than the 'natural' rythm of replacement of capital $1 / \tau$, there are no adjustment costs and the reduction cost is proportional to $x^{2}$. Above that rythm, costs would be multiplied by $\max \left(1, x^{\prime} \tau\right)$. See equation 6bis. We also present in Table 4 the results with the 6bis cost function, to show that our core results are not very sensitive to the exact form of the cost function choosen.

\section{Pathways under stabilisation constraints}

We initially explore results under two concentration ceilings: 450ppm and 550ppm. The ceiling 450ppm leads to a total radiative forcing that may be roughly equivalent to a doubling of pre-industrial $\mathrm{CO}_{2}$ concentrations, when other greenhouse gases are taken into account, which has been the benchmark for most climate model analyses of future equilibrium climate change. 550ppm represents the level given greatest attention in the WRE paper, which with other gases substantially exceeds a doubling of $\mathrm{CO}_{2}$-equivalent.

Figure 2 illustrates the global emission pathways that minimise abatement costs under 450ppm and 550ppm for two cases: $\tau=50$ and $\rho=3 \%$ (case A) and $\tau=20$ years and $\rho=5 \%$ (case B), compared against the reference path. In $450 \mathrm{~A}$ global $\mathrm{CO}_{2}$ emissions increase little, returning to current levels shortly after 2020 (when they are $24 \%$ below reference levels); for $550 \mathrm{~A}$ they peak at higher levels around 2050. 550B approximates the characteristics of the economic analyses cited by WRE, and their results. Our sensititives studies around 550ppm (Table 4) suggest that increased inertia results in stronger earlier abatement: with lower inertia (B), there is less initial abatement and emissions peak higher but then decline more steeply. Departure from the reference trajectory over the next 1-2 decades is modest for $550 \mathrm{~B}$, somewhat greater for 550A, and much greater for the $450 \mathrm{ppm}$ cases especially $450 \mathrm{~A}$.

This is reflected in the cost of delay, which is positive in all cases. Delay until 2020 increases the total discounted costs by $8-10 \%$ for the $550 \mathrm{ppm}$ cases with $\tau=50$ years, but only by $2-3 \%$ if $\tau=20$ yeas; for $450 \mathrm{ppm}$ the increase is in the range $32-70 \%$ for the $450 \mathrm{ppm}$ cases (Table 4).

Figure 3 provides insight into these results in terms of the abatement expenditure over time for $\tau=50$ trajectories, which for the reasons given we consider to be a more realistic representation of the full inertia in global energy systems (for $\tau=20$ results see Table 2). If abatement is not allowed to start until 2020 (but then follows an optimal trajectory), expenditure jumps sharply in the $450 \mathrm{~A}$ case, to three times the peak level without such a delay. The increase for the 550A case is modest, and furthermore is heavily discounted as most of the expenditure arises after the middle of the next century. The benefits of early action, though positive, are not nearly as large when the time to stabilisation in the reference case is significantly greater than the characteristic time of the energy system (as in the 550ppm cases).

\section{Impacts of uncertainty in the stabilisation limit}


Ha-Duong M. (1997) Necessities and problems of coupling climate and socioeconomic models for integrated assessments studies from an economist's point of view

Huge uncertainty surrounds the climate problem; the Convention itself emphasises the need for policies to adjust in the light of accumulating knowledge. To analyse optimal trajectories when the stabilisation constraint is uncertain, we assume a probability distribution of a range of possible stabilisation contraints, and we assume that the uncertainty is resolved at time $\mathrm{T}_{\text {info }}$. In this stochastic version of DIAM, before $\mathrm{T}_{\text {info }}$, the model finds the pathway that minimises the expected value of abatement costs, that represents a 'hedging strategy' against the uncertainties.

The three cases U550A-C specified in Table 4 each represent cases in which the $\mathrm{CO}_{2}$ stabilisation ceiling is distributed equally between 450, 550 and $650 \mathrm{ppm}$ (ie. with mean $550 \mathrm{ppm}$ ) and the uncertainty is resolved in 2020. In each case, the optimal degree of abatement by 2020 is substantially greater than for the equivalent deterministic case for 500ppm: $9-14 \%$ against $3-7 \%$. This is because the cost of switching to stay within $450 \mathrm{ppm}$ too late dominates the incremental cost of a path that follows a lower trajectory up to 2020 , and then can relax abatement in the event of 'good news' about climate change (eg. allowing $650 \mathrm{ppm}$ or higher ceiling). This effect is all the more important if the resolution of uncertainty comes later: in U555L the uncertainty is not resolved until 2035, and abatement is greater again.

The qualitative conclusion is robust to the assumed degree of inertia and discounting: even with assumptions corresponding to most of the models cited by WRE, the abatement under uncertainty (U550B) at 2020 is $9 \%$ compared with 5\% for the deterministic case.The difference falls below $2 \%$ only for absurdly low values of inertia (10-12 years).

These results reflect directly the inertia of large-scale industry and the cost of misallocating capital investment. In a situation of high uncertainty and inertia, policy conclusions cannot simply be referred to mean estimates of the constraint. If we were certain that atmospheric $\mathrm{CO}_{2}$ concentrations could safely reach 550ppm or higher (which with other gases corresponds to over $650 \mathrm{ppm}$ in $\mathrm{CO}_{2}$ equivalent), then deferring abatement by a couple of decades would be unlikely to increase total discounted abatement costs by more than $10 \%$. However if 550ppm is a mean estimate of a much broader range of possible constraints, the costs of this sub-optimal trajectory may prove far greater than erring on the side of caution.

\section{Discussion}

These numerical experiments show the importance for policy of considering both inertia and uncertainty in systems that produce greenhouse gas emissions, so as to minimise future peaks in the rates of abatement and prevent possible draconian costs if tighter-than-expected constraints prove necessary. As with any such numerical projections, the qualitive conclusions are more important than the specific numerical results. . If the atmosphere must eventually be stabilised, deferring all abatement is never optimal, but the costs of deferring abatement are higher under the conditions of high inertia and uncertainty that characterise the real-world climate problem. Inertia indeed has a 'Janus's' role, raising both the costs of premature abatement and the costs of further acceleration in the event of delayed action. It makes steady precautionary abatement more cost-effective: without any inertia, there would be no transition costs in switching from one path to another, action could be deferred until very close to the limit and uncertainty would matter far less.

We also emphasise that our results reflect deviation from a reference case that is assumed to be optimal in the absence of constraints; the IPCC recognised that there are some 'free' emission reductions, and to the extent that this might make a least-cost path lower than our reference scenario, this would reduce absolute emission levels correspondingly. We also 
Ha-Duong M. (1997) Necessities and problems of coupling climate and socioeconomic models for integrated assessments studies from an economist's point of view

acknowledge that some precautionary abatement may be an effective way of learning how to make abatement less costly in the future, which is not captured in our analysis.

This analysis, like those of WRE and its references, treats the stabilisation constraint as inviolable and does not take any direct account of climate impacts. In reality the choice of stabilisation level reflects judgement about the balance of costs and risks. Deferring abatement also results in higher rates of climate change that may be significant. An analysis that seeks directly to trade off abatement costs against the full benefits of reduced climate change is economically more rigorous in theory, but in these circumstances, assumptions about the nature of the damage function and the degree of induced technical change, which are both very uncertain, become critical, and this would obscure the basic insights arising from WRE's analysis and our paper

We also note that precautionary abatement may be an effective way of learning how to make abatement less costly in the future. Our analysis has treated technical progress as exogenous; but experience demonstrates the role of learning-by-doing and economies to scale in the real world, which may also increase the costs of deferring abatement.

\section{Conclusion: How to make these models more policy relevant ?}

Using DIAM, we have been able to underline the economic risks of installing costly energy and transportation infrastructure that may have to be scrapped in future years, and the importance of understanding the balance of risks in systems of high inertia and great uncertainty. Early attention to the carbon content of new equipments reduces the exposure of both the environmental and the economic systems to the risks of unpleasant and costly surprises.

To conclude that presentation, I would like to summarize, first, aspects that economists think they understand clearly, to be distinguished, second, from aspects that we think important but not yet understood. Other aspects will be left to your personal reflections. With this division, we hope to make it obvious the distinction between economics as a science and a political tool. We also insist that if we do IAM, this is because we recognize that economic consideration alone are not sufficient for analysis.

\section{Things we think we understand}

Straighforward reasoning suggests that if we are to set a concentration target at or over 550 ppmv, then waiting a decade or two is sensible (WRE remark). This arises from three economic facts rather well established from past experiences.

- Future generations are likely to be better off that we are, so what we have to do against climate change can be seen as the poor (us) giving their resources to increase the well being of the riches (future generations).

- There has been a continuous technical progress and it doesn't seems to be slowing down, on the contrary. In the information-oriented society that is to come soon, material goods and the carbon emission they implies will be less critical to the well being of people.

- We have to account for the installed material capital: re-engineering industrial processes and rewamping plants are naturally done when they become obsolete. Since before the end of the next century most capital will have been replaced at least two times, we should build upon that opportunity to avoid accelerating the obsolescence of capital. This also 
Ha-Duong M. (1997) Necessities and problems of coupling climate and socioeconomic models for integrated assessments studies from an economist's point of view

include the institutions, as rapid reallocation of work forces, for examples, are often done at a considerably high social cost.

But then economics also make the following two points quite clear:

- Because new capital is always being installed, the issue of installed capital will be as serious in 20 years as it is today. So the converse of WRE remark also true: if we wait, then we will be economically unable to achieve 450ppmv.

- Because of the huge uncertainties surrounding the climate change issues, looking at the 'best' way to achieve a given concentration target is not the best way to frame the issue. We should rather examine how to adopt a prudent strategy in the face of ignorance about the appropriate ultimate target.

In addition to those five points, one could regard with confidence the result on where and when flexibility:

- Allowing emission reductions to occur where they are least costly, and when they are least costly, can reduce the cost by a significant amount.

The above list does not mean that things are perfectly clear on those issues, far from that. It rather means that some IAMs have been discussing them and that we are rather confident about the sign of their overall policy implications.

\section{Things we think are important but not so clear (yet?)}

Although IAMs are needed to put some rationality in the decision making process, they are still far from being realistic. They still face challenges such as representation and valuation of climate change impacts, critical issues in developping countries, technological change, uncertainty and irreversibility, and economic instruments to implement policies. These are only from an economist point of view, and are explained in the 2 pages summary of Weyant ${ }^{1}$ paper distributed at the conference. Considerations of political sciences such as negociability, joint implementation, joint equity and efficiency effects should be and actually are excluded from IAMs.

To tackle these challenges, scientific control of IAMs will be a primary issue, because by definition interdisciplinary research whereas people, as are organisations, are specialized. But the field is very young, less than fifteen years, and very active, so the progress rate is high. There will also be managerial, mathematical and computing obstacles. To overcome these will need lots of bright minds working together. This is a call to all the young scientists attending this conference. IAM are necessary and useful, they are also exciting to work with.

\section{References}

\footnotetext{
${ }^{1}$ Weyant P. John, (1996) Insights from Integrated Assessment. Communication at the IPIECA Symposium on Critical Issues in the Economics of Climate Change, Paris, 8-11 October 1996.

${ }^{2}$ Wigley T.M.L., Richels R., Edmonds J. (1996). Economic and environmental choices in the stabilisation of atmospheric $\mathrm{CO}_{2}$ concentrations, Nature Vol. 379, 18 January 1996.

${ }^{3}$ Grubb M.J., Chapuis T. and Ha-Duong M. (1995). The economics of changing course : Implications of adaptability and inertia for optimal climate policy, Energy Policy, Vol. 23, No. 4/5, April/May 1995, 417-432.
} 
Ha-Duong M. (1997) Necessities and problems of coupling climate and socioeconomic models for integrated assessments studies from an economist's point of view

Table 3: DIAM2: a stochastic dynamic programming Model on the Dynamics of Inertia and Adaptability for integrated assessment of climate change mitigation

t, u refers to time periods, s refers to states of the world ( $=$ "L"ow, "C"entral, "H"igh ceiling)

\section{Exogenous parameters}

$\mathrm{E}^{\mathrm{ref}}(\mathrm{t}) \quad$ Reference anthropogenic fossil carbon emissions

$\mathrm{M}^{\text {ref }}(\mathrm{t}) \quad$ Reference $\mathrm{CO}_{2}$ concentration path

$\mathrm{R}(\mathrm{u}) \quad$ Atmospheric perturbation $\mathrm{CO}_{2}$ response function

$\mathrm{p}(\mathrm{s}) \quad$ Subjective probability distribution for concentration ceilings

L(s) Levels of concentration ceilings

$t_{\text {info }} \quad$ Date of resolution of uncertainty regarding the concentration ceiling

$\rho \quad$ discount rate

$\mathrm{r} \quad$ rate exogenous decline in reduction costs (technical progress)

$\mathrm{c}_{\mathrm{a}}, \mathrm{c}_{\mathrm{b}} \quad$ parameters of the additive cost function

$\mathrm{c}_{\mathrm{k}}, \mathrm{D} \quad$ parameters of the multiplicative cost function

\section{Endogenous variables}

$x(\mathrm{~s}, \mathrm{t}) \quad$ Abatement level (Policy variable)

$\mathrm{C}(\mathrm{s}, \mathrm{t}) \quad$ Abatement costs

$\mathrm{M}(\mathrm{s}, \mathrm{t}) \quad$ Atmospheric concentration of $\mathrm{CO}_{2}$

$\mathrm{A}(\mathrm{s}, \mathrm{t}) \quad$ Acceleration of abatement

J Total expected discounted abatement cost

\section{Equations}

(Eq. 1) $\quad \operatorname{Min}_{\varepsilon} J=\sum_{s} p(s) \sum_{t}(1+\rho)^{t_{0}-t} C(s, t)$

subject to

(Eq. 2) $\quad \forall \mathrm{t} \leq \mathrm{t}_{\text {info }}, x(\mathrm{~L}, \mathrm{t})=x(\mathrm{C}, \mathrm{t})=x(\mathrm{H}, \mathrm{t})$

$$
\mathrm{u}=\mathrm{t}-1
$$

(Eq. 3) $\quad \mathrm{M}(\mathrm{s}, \mathrm{t})=\mathrm{M}^{\mathrm{ref}}(\mathrm{t})-0.471 \quad \sum \mathrm{R}(\mathrm{t}-\mathrm{u}) \varepsilon(\mathrm{s}, \mathrm{u}) \mathrm{E}^{\mathrm{ref}}(\mathrm{u})$

$$
\mathrm{u}=\mathrm{t}_{0}
$$

(Eq. 4) $\quad \mathrm{M}(\mathrm{s}, \mathrm{t}) \leq \mathrm{L}(\mathrm{s})$

(Eq. 5) $\quad \mathrm{A}(\mathrm{s}, \mathrm{t})=x(\mathrm{~s}, \mathrm{t})-x(\mathrm{~s}, \mathrm{t}-1)$

(Eq. 6) $\quad \mathrm{C}(\mathrm{s}, \mathrm{t})=(1+\mathrm{r})^{\mathrm{t} 0-\mathrm{t}} \frac{\mathrm{E}^{\mathrm{ref}}(\mathrm{t})}{\mathrm{E}^{\mathrm{ref}}\left(\mathrm{t}_{0}\right)}\left(\mathrm{c}_{\mathrm{a}} x(\mathrm{~s}, \mathrm{t})^{2}+\mathrm{c}_{\mathrm{b}} \mathrm{A}(\mathrm{s}, \mathrm{t})^{2}\right)$

(Eq. 6 bis) $C(s, t)=(1+r)^{t 0-t} \frac{E^{r e f}(t)}{E^{r e f}\left(t_{0}\right)} c_{k} x(s, t)^{2} \max (1, D A(s, t))$ 
Ha-Duong M. (1997) Necessities and problems of coupling climate and socioeconomic models for integrated assessments studies from an economist's point of view

Table 4 :Results of DIAM2 for certainty scenarios and hedging strategies

\begin{tabular}{|c|c|c|c|c|c|c|c|c|c|}
\hline $\begin{array}{l}\text { Certainty } \\
\text { scenarios }\end{array}$ & $\begin{array}{c}\tau \\
\mathbf{y r}\end{array}$ & $\rho$ & $\begin{array}{c}\text { S } \\
\text { ppmv }\end{array}$ & $\mathbf{t}_{\text {stab }}$ & $x_{2020}$ & $\begin{array}{c}x_{2020} \\
(\#) \\
\end{array}$ & $\begin{array}{l}E_{\max } \\
\text { GtC }\end{array}$ & $\mathbf{t}_{\mathbf{E}_{\max }}$ & $\begin{array}{c}\text { Cost of } \\
\text { delay }\end{array}$ \\
\hline $450 \mathrm{~A}$ & 50 & $3 \%$ & 450 & 2060 & $24 \%$ & $19 \%$ & 8.7 & 2015 & $+70 \%$ \\
\hline $450 \mathrm{~B}$ & 20 & $5 \%$ & 450 & 2050 & $19 \%$ & $14 \%$ & 9.2 & 2015 & $+32 \%$ \\
\hline $450 \mathrm{C}$ & 50 & $5 \%$ & 450 & 2050 & $20 \%$ & & 9.1 & 2015 & $+72 \%$ \\
\hline 450D & 20 & $3 \%$ & 450 & 2060 & $23 \%$ & & 8.8 & 2015 & $+25 \%$ \\
\hline $550 \mathrm{~A}$ & 50 & $3 \%$ & 550 & 2100 & $7 \%$ & $4 \%$ & 11.5 & 2050 & $+10 \%$ \\
\hline $550 \mathrm{~B}$ & 20 & $5 \%$ & 550 & 2080 & $3 \%$ & $2 \%$ & 12.6 & 2050 & $+2 \%$ \\
\hline $550 C^{*}$ & 50 & $5 \%$ & 550 & 2090 & $4 \%$ & $2 \%$ & 12.2 & 2050 & $+8 \%$ \\
\hline $550 \mathrm{D} *$ & 20 & $3 \%$ & 550 & 2090 & $5 \%$ & $4 \%$ & 11.9 & 2050 & $+3 \%$ \\
\hline $650 A^{*}$ & 50 & $5 \%$ & 650 & 2125 & $3 \%$ & $0 \%$ & 14.1 & 2070 & $+4 \%$ \\
\hline $\begin{array}{c}\text { Hedging } \\
\text { strategies } \\
\end{array}$ & $\begin{array}{c}\tau \\
\mathbf{y r}\end{array}$ & $\rho$ & $\mathbf{t}_{\text {info }}$ & $\begin{array}{l}\mathbf{E}_{2020} \\
\text { GtC }\end{array}$ & $x_{2020}$ & $\begin{array}{c}x_{2020} \\
(\#) \\
\end{array}$ & $x_{2010}$ & & \\
\hline U550A & 50 & $3 \%$ & 2020 & 9.6 & $14 \%$ & $14 \%$ & $8 \%$ & & \\
\hline U550B & 20 & $5 \%$ & 2020 & 10.1 & $9 \%$ & $6 \%$ & $4 \%$ & & \\
\hline U550C* & 50 & $5 \%$ & 2020 & 9.9 & $11 \%$ & $13 \%$ & $6 \%$ & & \\
\hline U550L (late) & 50 & $3 \%$ & 2035 & 8.9 & $21 \%$ & $17 \%$ & $12 \%$ & & \\
\hline
\end{tabular}

* Not shown on illustrations below to avoid crowding.

\# Multiplicative cost function.

\section{Figure 2. Optimal emissions pathways under stabilisation constraints}

The figures show pathways that minimise the total abatement costs for the given concentration target. The $\mathrm{B}$ cases have lower inertia and higher discount rate than A, both these factors leading to higher near-term optimal emissions: see Table 3.

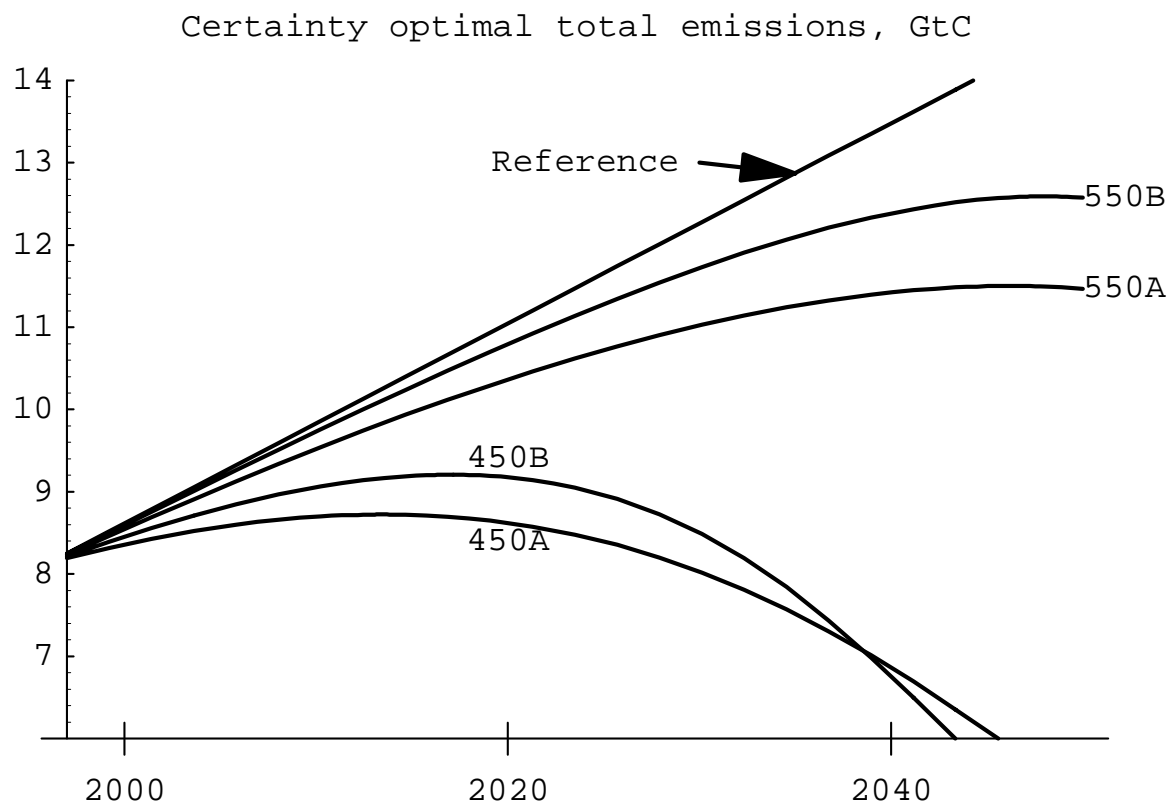


Ha-Duong M. (1997) Necessities and problems of coupling climate and socioeconomic models for integrated assessments studies from an economist's point of view

\section{Figure 3. Optimal expenditure profiles under stabilisation constraints}

Current expenditure profiles with (dashed lines) and without (solid lines) a 20 years delay, for 450 and $550 \mathrm{ppm}$ stabilisation targets (case A). For $450 \mathrm{ppm}$, the cost peaks abruptly and much higher with defferal than without, due to higher adjustment costs in the 2020 - 2040 period. Results are not that sharp for $550 \mathrm{ppm}$, as the time available to stabilize at this level (or above) exceeds the characteristic time of the global energy system. Unit is $\%$ of 1990 world gross product, calibrated so that the total cost is comparable to the one in DICE [8], however the relative shape of emission and expenditure paths are independant of the scale of the abatement costs.

Current expenditure

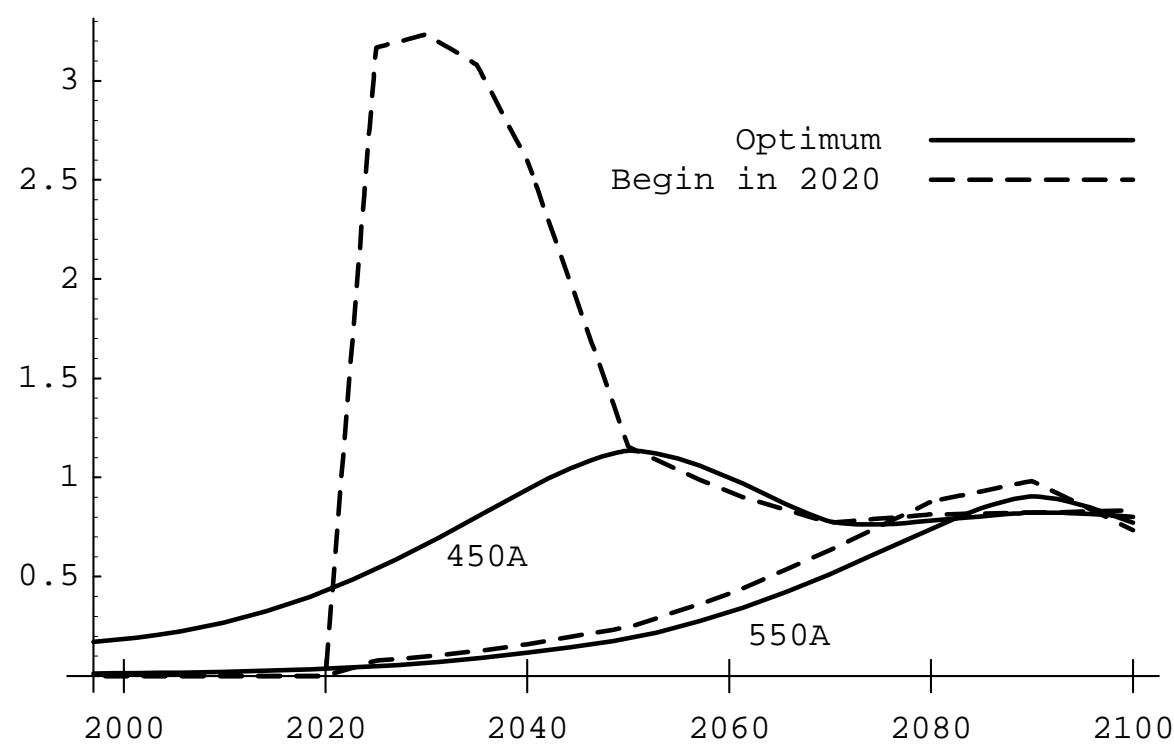

\section{Figure 4 : Optimal global emission strategies under stochastic constraints}

Reference case : 2\%/year linear increase (assumed least cost). For key see Table 3. The ultimate target is decided only in 2020 (2035 for U550L).

Hedging optimal total emissions, GtC

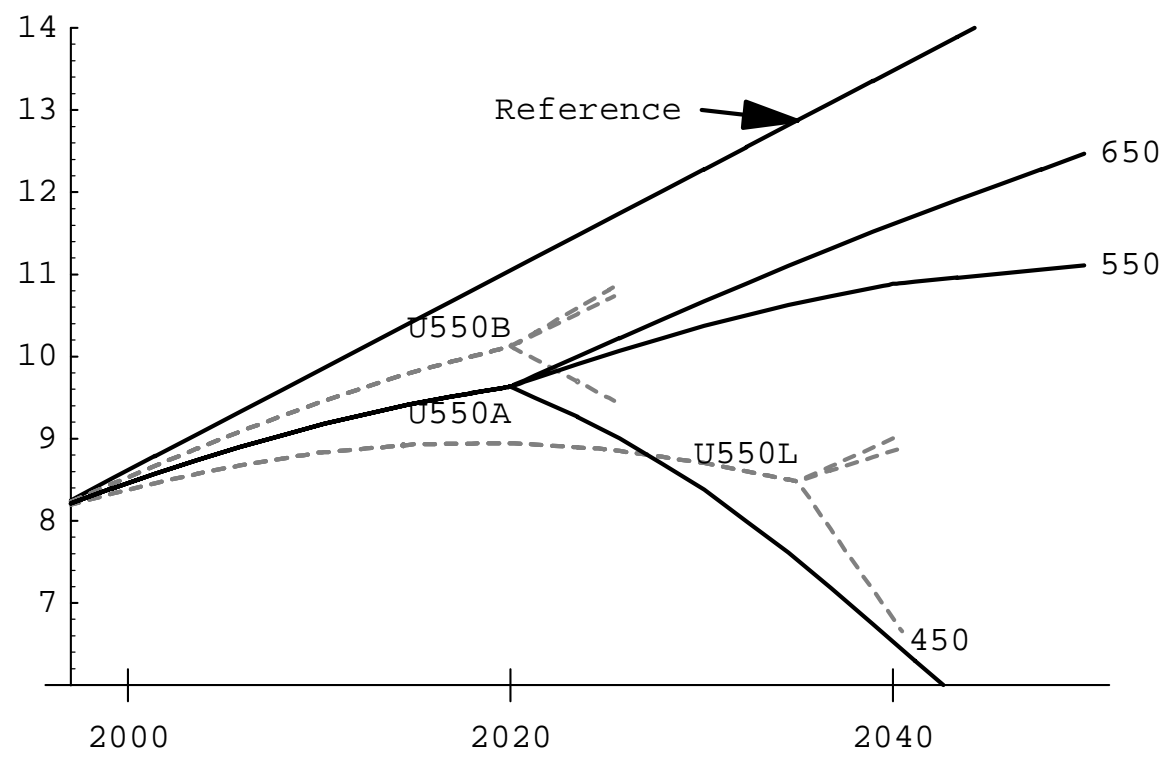

